\title{
Garcinia mangostana: a source of potential anti-cancer lead compounds against CEM- SS cell line
}

\begin{abstract}
Our current interest in searching for natural anti-cancer lead compounds from plants has led us to the discovery that the stem and roots of Garcinia mangostana can be a source of such compounds. The stem furnished 2,8-dihydroxy-6-methoxy-5-(3-methylbut-2-enyl)-xanthone (1), which is a new xanthone. Meanwhile, the root bark of the plant furnished six xanthones, namely -mangostin (2), $\beta$-mangostin (3), $\gamma$-mangostin (4), garcinone D (5), mangostanol (6), and gartanin (7). The hexane and chloroform extracts of the root bark of G. mangostana as well as the hexane extract of the stem bark were found to be active against the CEM-SS cell line. $\gamma$-Mangostin (4) showed good activity with a very low IC50 value of $4.7 \mu \mathrm{g} / \mathrm{ml}$, while mangostin (2), mangostanol (6), and garcinone D (5) showed significant activities with IC50 values of $5.5,9.6$, and $3.2 \mu \mathrm{g} / \mathrm{ml}$, respectively. This is the first report on the cytotoxicity of the extracts of the stem and root bark of G. mangostana and of -mangostin, mangostanol, and garcinone D against the CEM-SS cell line.
\end{abstract}

Keyword: Garcinia mangostana; xanthones; cytotoxicity; CEM-SS cell line 